\title{
Experimental Evaluation of Ultra Wideband Propagation and Transmission within a Small Spacecraft for Replacing Wired Interface Buses
}

\author{
Miyuki Hirose, Takehiko Kobayashi \\ Wireless Systems Laboratory, Tokyo Denki University, Tokyo, Japan \\ Email: miyuki@mail.dendai.ac.jp
}

How to cite this paper: Hirose, M. and Kobayashi, T. (2019) Experimental Evaluation of Ultra Wideband Propagation and Transmission within a Small Spacecraft for Replacing Wired Interface Buses. Int. J. Communications, Network and System Sciences, 12, 59-73.

https://doi.org/10.4236/ijcns.2019.125006

Received: January 31, 2019

Accepted: May 28, 2019

Published: May 31, 2019

Copyright $\odot 2019$ by author(s) and Scientific Research Publishing Inc. This work is licensed under the Creative Commons Attribution International License (CC BY 4.0).

http://creativecommons.org/licenses/by/4.0/

(c) (i) Open Access

\begin{abstract}
Measurement and characterization of ultra wideband (UWB) propagation and transmission within small spacecrafts were investigated with a view to (at least partly) displacing wired interface buses in spacecrafts with wireless links. Measurements were conducted in a mechanical test model of a small spacecraft and an equivalent shield box. The impact of apertures perforated on the outer surface and radio absorbers within the box were also examined. The following properties were derived there from: channel responses in the frequency- and time-domain, spatial distributions of UWB and narrowband propagation gains, delay spreads, and throughputs, the relation between delay spread and area of apertures and the absorber, and the relation between fading depth and the bandwidth. On the effects of apertures, the larger total area of apertures resulted in lower UWB propagation gains, shorter delay spreads, and slightly higher link throughput. Commercially off-the-shelf UWB devices were used in the experiments of UWB technology to facilitate a high data rate.
\end{abstract}

\section{Keywords}

Ultra Wideband, Satellite Bus, Propagation Loss, Delay Spreads,

Transmission

\section{Introduction}

The volume and weight of cables for connecting subsystems used for spacecrafts are increasing due to diversified onboard mission systems. Furthermore, since wire harnesses and cables are assembled manually for the most part, the cable assembly has resulted in high costs and long lead times [1]. Wireless technologies have not been utilized within spacecrafts as a physical layer of the interface 
buses, because of their problems of unreliability and electromagnetic compatibility with other onboard systems. Adoption of wireless systems, however, within the spacecrafts could contribute to:

- reduction of cable weight and launching cost as a result;

- reduction in the cost of manufacture;

- more flexibility in layout of spacecraft subsystems;

- highly reliable connection at rotary, moving, and sliding joints.

To realize these benefits, multipath propagation (namely reflected from the nearby walls) affecting the transmission performance must be scrutinized. Several studies have been reported about radio propagation in spacecrafts for wireless links [2] [3] [4] [5]. Narrowband wireless links within a spacecraft were numerically calculated and experimentally evaluated in [2] [3]. An overview of the different bit error rate (BER) calculated in presence of multipath and narrowband interference due to the spacecraft environment [4]. In [5] [6], propagation channel measurements were performed for cable replacement inside a spacecraft. While narrowband wireless systems suffer flat fading in the multipath environments, and thus need a substantial amount of fading margin, ultra wideband (UWB) systems intrinsically feature anti-multipath capabilities. Wideband and ultra wideband propagation in closed and semi-closed environments were measured and characterized: an automobile [7], an aircraft cabin [8], and a PC case [9]. We were considering the use of UWB for reliable connections inside the spacecrafts and experimentally evaluated UWB radio propagation in a small scientific spacecraft for replacing wired interface buses with wireless links [5] [10]. Path gains and throughputs were also measured for various antenna settings and polarizations in the small spacecraft [10] [11].

In this paper wideband and UWB propagation and transmission were measured in a mechanical test model (MTM) of a small spacecraft and an equivalent shield box. Section II describes measurements and characterization of UWB propagation within an MTM. Section III and IV present UWB propagation and transmission within an electric shield box and focus on the effect of apertures (perforated on the outer surface of the box) and radio absorbers, respectively. Section V concludes this paper.

\section{Measurements within a Small Spacecraft}

\subsection{Measurement Setup}

An MTM of a small scientific satellite and a shield box with the same size were used for this measurement in Figure 1. The MTM was a rectangular parallelepiped, $430 \mathrm{~mm}$ long $\times 470 \mathrm{~mm}$ wide $\times 435 \mathrm{~mm}$ high, enclosed in flat honeycomb panels made of aluminum, excluding its solar panels [12]. Its interior was divided into two almost equal subspaces by a conductive partition having many openings, and filled with mission subsystems. Although no electric or electronic components were equipped, conductive boxes and cable assemblies inside the MTM were exactly the same as the actual spacecraft. The transmitting 
and receiving antennas were omnidirectional, vertically polarized, low voltage-standing-wave-ratio UWB monopole antennas [13]. Their circular ground planes were $100 \mathrm{~mm}$ in diameter. Within the MTM, the transmitting antenna was fixed in one subspace and the receiving antenna was scanned in another, as shown in Figure 1. This position was defined the origin of the Cartesian coordinate, whose $x, y$, and $z$ axes were parallel to the sides of MTM. The receiving antenna was scanned within a region $200 \leq x[\mathrm{~mm}] \leq 300$ and $-140 \leq y[\mathrm{~mm}] \leq$ 140 in 5-mm intervals on a styrofoam stage (transparent to electromagnetic waves). The feeding coaxial cables penetrated through the observation windows on the sides. During the measurements, the conductive top lid was closed.

Frequency- and time-domain propagation gains were measured with a microwave vector network analyzer (VNA). Major specifications of the measurements are listed in Table 1 . The UWB propagation gains were calculated by integrating the power of the losses between the feeding points of the antennas over occupied bandwidth, as follows:

$$
P L_{d B}=10 \log \left(\frac{1}{f_{H}-f_{L}}\right) \int_{f_{L}}^{f_{H}} 10 \frac{P L_{d B}(f)}{10} d f[\mathrm{~dB}]
$$

The continuous wave (CW) propagation gains at the center frequency $(=6.85$ $\mathrm{GHz}$ ) were extracted therefrom. Root-mean-square delay spread was calculated from the power delay profile $P\left(\tau_{i}\right)$, where $\tau_{i}$ is the $i$-th path delay. Delay spread $S$ is then defined by the square root of the second central moment of the delay profile:

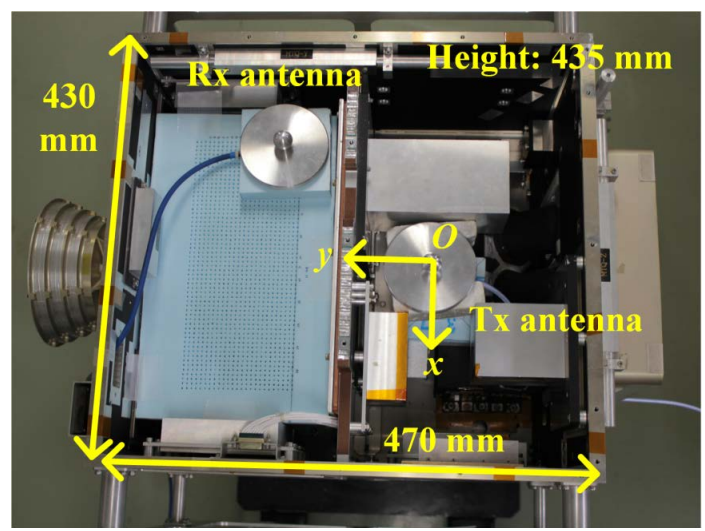

Figure 1. Measurement setup within MTM.

Table 1. Specifications of the microwave vector network analyzer.

\begin{tabular}{cccc}
\hline Model & \multicolumn{3}{c}{ Agilent E8362B } \\
\hline Bandwidth & $\begin{array}{c}3.1-10.6 \mathrm{GHz} \\
\text { (full-band) }\end{array}$ & $\begin{array}{c}4.2-4.8 \mathrm{GHz} \\
\text { (low-band) }\end{array}$ & $\begin{array}{c}7.4-7.9 \mathrm{GHz} \\
\text { (high-band) }\end{array}$ \\
$\begin{array}{c}\text { Frequency sweeping } \\
\text { points by VNA } \\
\text { Calibration }\end{array}$ & 7501 & 601 & 501 \\
\hline
\end{tabular}




$$
S=\sqrt{\frac{\sum \tau_{i}^{2} P\left(\tau_{i}\right)}{\sum P\left(\tau_{i}\right)}-\left(\frac{\sum \tau_{i} P\left(\tau_{i}\right)}{\sum P\left(\tau_{i}\right)}\right)^{2}}
$$

where the summations are taken above a threshold level $-20 \mathrm{~dB}$ below the maximum of $P\left(\tau_{i}\right)[9]$.

WiMedia [13] was used for the experiments of UWB technology to facilitate a high data rate up to $480 \mathrm{Mbps}$ for wireless USB 2.0 applications. Note that maximum of $212 \mathrm{Mbps}$ per node attained with SpaceWire [14], equaling the standards of a wired onboard data bus. Its major specifications are listed in Table 2. The WiMedia, a high-speed wireless personal area communication standard, utilizes a multiband quadrature phase shift keying-orthogonal frequency division multiplexing (QPSK-OFDM) bundling up to 14 subbands each of which occupies $528 \mathrm{MHz}$. The cyclic prefix (prefixing of a symbol) used in OFDM provides a guard interval to eliminate intersymbol interference between the OFDM symbols. The multiband-OFDM employs 60.61-ns zero postfix. When the delay spreads are sufficiently shorter than $60.61 \mathrm{~ns}$, therefore, the WiMedia devices can be used, which yield the maximum data rate of $480 \mathrm{Mbps}$, within the spacecrafts. Nonetheless, nominal bit rate of the device under test in this paper was $72 \mathrm{Mbps}$ according to specifications.

\subsection{Measurement Results}

The spatial distributions of propagation gains for $\mathrm{CW}, 10-\mathrm{MHz}$, and $7.5-\mathrm{GHz}$ (the full band UWB) bandwidths within the MTM are shown in Figure 2. The UWB propagation gains did not exhibit explicit dependence on distance, whereas the IEEE 802.15.3a channel model applicable to indoor environments used the path loss increasing with the square of distance. While $\mathrm{CW}$ resulted in up to $28 \mathrm{~dB}$ fading at several "dead spots" caused by multipath interference, UWB practically yielded no dead spots. While narrowband wireless systems suffer flat fading in the multipath environments, and thus need a substantial amount of fading margin, UWB systems inherently possess anti-multipath capabilities. The cumulative distribution functions (CDFs) of propagation gains within MTM are illustrated in Figure 3. A bandwidth over $400 \mathrm{MHz}$ was capable of reducing the fading depth to approximately $2 \mathrm{~dB}$ for the MTM [10].

The CDFs of the delay spreads derived from measured delay profiles for full-, low-, and high-band UWB, as shown in Figure 4. The CDFs of the throughputs measured with the low- and the high-band UWB WiMedia devices are plotted in Figure 5. Apparently line-of-sight (LOS) resulted in higher throughputs than non-LOS (NLOS), while no significant differences were observed between the low- and the high-band UWBs. Various combinations of antenna, setting and polarization configuration were examined, within the same MTM. Polarization configurations were found to produce almost no effect on average power delay profiles and substantially small effects on the throughputs [11]. Matsushita et al. [15] also revealed that numerical transmission simulation resulted in sufficiently 
low bit error rates and high throughputs with use of time-domain propagation data measured in the MTM.

Table 2. Parameters of a WiMedia device under test.

\begin{tabular}{|c|c|c|}
\hline Nominal maximum bit rate & \multicolumn{2}{|c|}{$72 \mathrm{Mbps}$} \\
\hline Bit rate & \multicolumn{2}{|c|}{$480 \mathrm{Mbps}$} \\
\hline Modulation & \multicolumn{2}{|c|}{ QPSK-OFDM } \\
\hline Frequency & \multicolumn{2}{|c|}{$\begin{array}{l}4.2-4.8 \mathrm{GHz} \text { (low-band) } \\
7.3-7.9 \mathrm{GHz} \text { (high-band) }\end{array}$} \\
\hline Number of subcarriers & $\begin{array}{l}\text { Totall } \\
\text { Data } \\
\text { Pilot } \\
\text { Guard } \\
\text { Null }\end{array}$ & $\left.\begin{array}{l}128 \\
100 \\
12 \\
10 \\
6\end{array}\right)$ \\
\hline Duration of cyclic prefix & \multicolumn{2}{|c|}{$60.61 \mathrm{~ns}$} \\
\hline
\end{tabular}

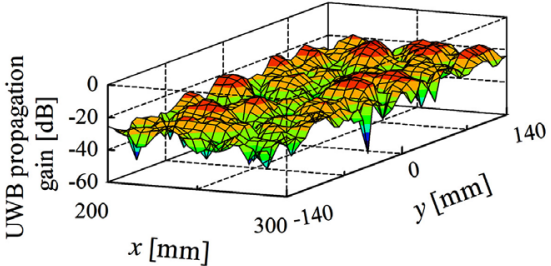

(a)

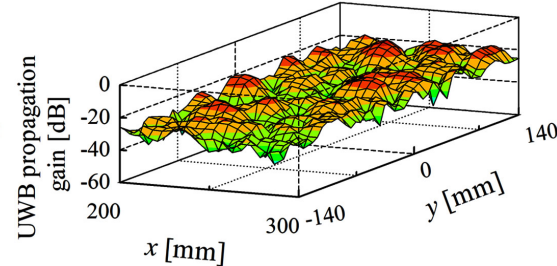

(b)

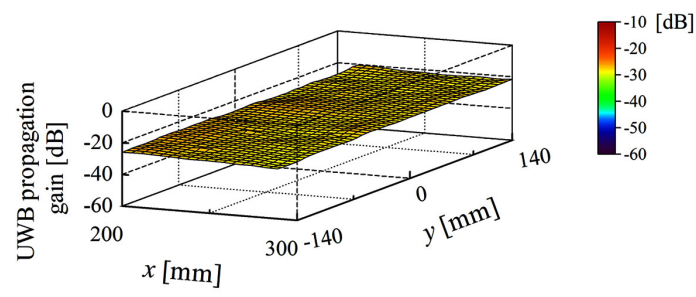

(c)

Figure 2. Distributions of propagation gains within MTM for: (a) CW, (b) $10-\mathrm{MHz}$, and (c) 7.5-GHz bandwidths.

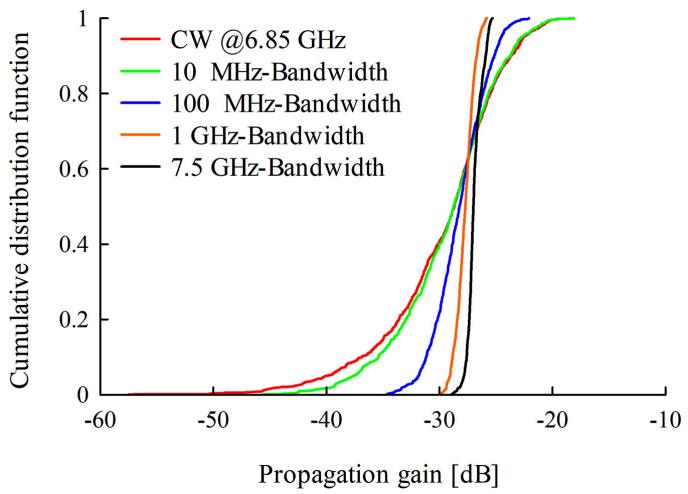

Figure 3. Cumulative distribution functions (CDFs) of UWB propagation gain measured within MTM. 


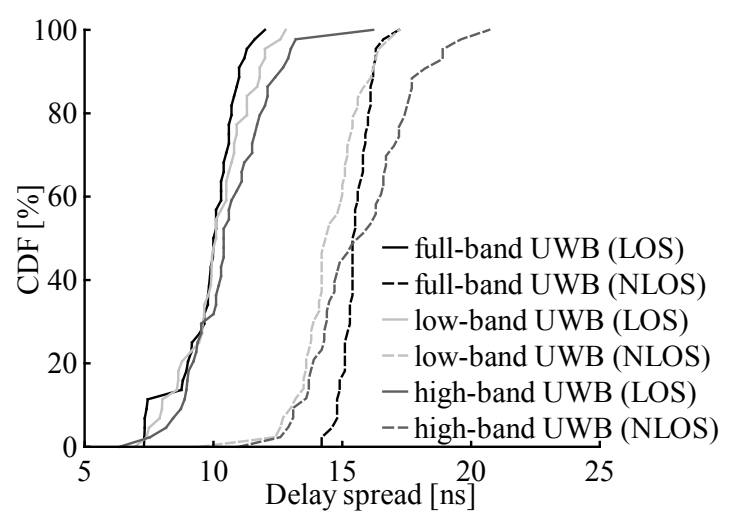

Figure 4. CDFs of delay spread within MTM.

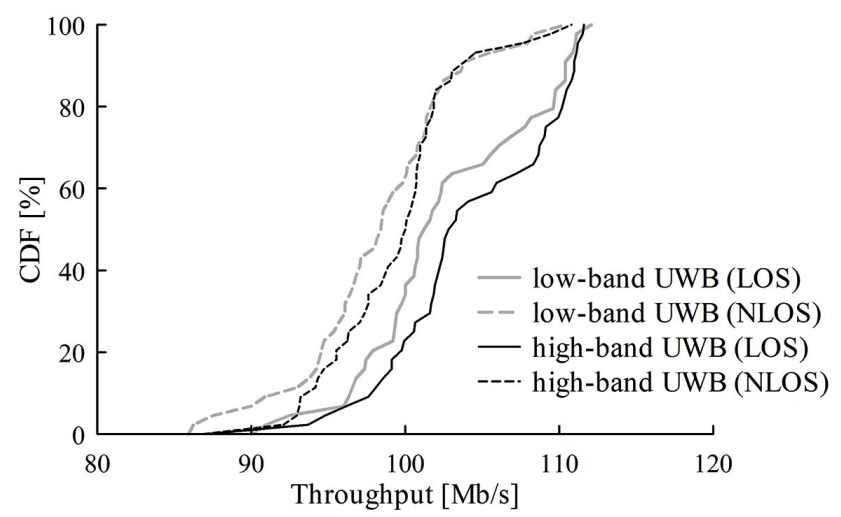

Figure 5. CDFs of UWB throughputs.

\section{Effects of Apertures on the Surface}

\subsection{Measurements Setup}

The shield box was employed to assess the whole inner space. The box had three $200 \mathrm{~mm} \times 200 \mathrm{~mm}$ square holes: one in the center of the top lid and the others in the center of both side surfaces, as partly appeared in Figure 6. For changing total area of apertures, conductive $240 \mathrm{~mm} \times 240 \mathrm{~mm}$ square panels with or without circular apertures were attached on the holes with use of conductive gaskets between mating surfaces. The diameter of the circular apertures was $12.5,25,50,100$, or $200 \mathrm{~mm}$. Within the shield box, the transmitting antenna was fixed at $250 \mathrm{~mm}$ above the bottom and adjacent to the center of a $430-\mathrm{mm}$ side, as shown in Figure 7. The receiving antenna was scanned within a region 0 $\leq x[\mathrm{~mm}] \leq 340$ and $-140 \leq y[\mathrm{~mm}] \leq 140$ in $20-\mathrm{mm}$ intervals on a polystyrene foam stage. Since the minimum distance between the antenna electric centers was $120 \mathrm{~mm}<\lambda_{L} / 2 \pi\left(\lambda_{L}\right.$ is the wavelength at the lowest frequency), all the measurements were carried out in a far-field region.

\subsection{Measurements Results}

Without apertures: The spatial distributions of CW and UWB propagation gains within the shield box are depicts in Figure 8, where no data exists in the 
vicinity of the origin (the transmitting antenna) [10]. While CW resulted in up to $35 \mathrm{~dB}$ fading at several "dead spots" caused by multipath interference, propagation gain variations were 4.7, and $4 \mathrm{~dB}$ for full-, low-, and high-band UWB, respectively. Cumulative distribution functions (CDFs) of the UWB propagation gain are plotted in Figure 9. The fading depths versus frequency bandwidth at the deepest dead spot in the shield box were derived from measured data, as shown in Figure 10, where the center frequency was fixed at $6.85 \mathrm{GHz}$, and the 7.5-GHz-bandwidth (from 3.1 to $10.6 \mathrm{GHz}$ ) propagation gain was set to the 0 - $\mathrm{dB}$ reference. A bandwidth over $400 \mathrm{MHz}$ (a fractional bandwidth over 6\%) was capable of reducing the fading depth to approximately $2 \mathrm{~dB}$ for the shield box. The UWB propagation gains did not exhibit explicit dependence on distance, whereas the IEEE 802.15.4a personal area network channel model [16] applicable to indoor environments used the path loss increasing with the square of distance. CDFs of the delay spreads derived from measured delay profiles within the shield box for full-, low-, and high-band UWB, as shown in Figure 11. Under these con ditions, the WiMedia device cannot be used, since delay spread exceeds the guard interval length.

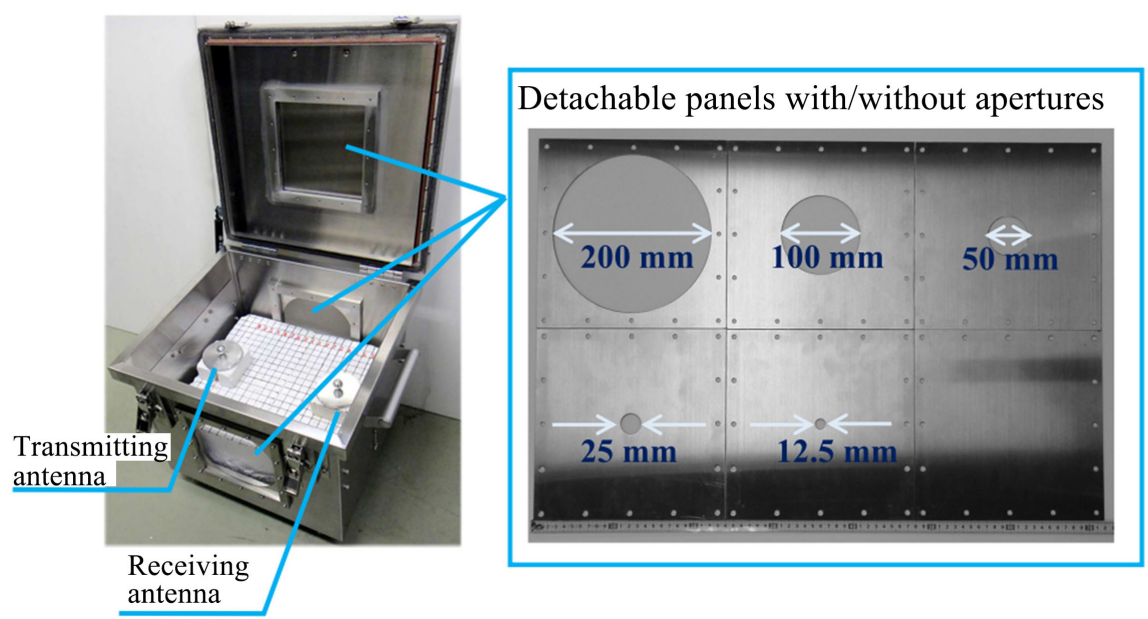

Figure 6. Measurement setup within the shield box and panels $(240 \mathrm{~mm} \times 240 \mathrm{~mm})$ with and without circular holes.

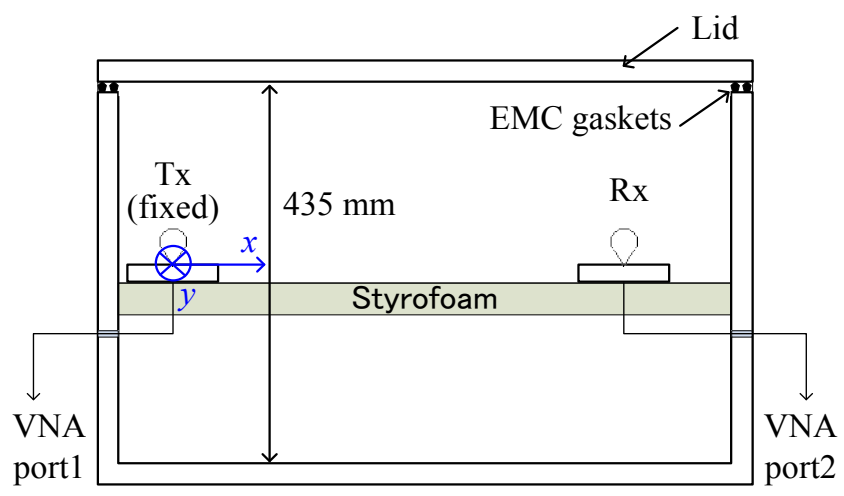

Figure 7. Antenna placements within the shield box. 


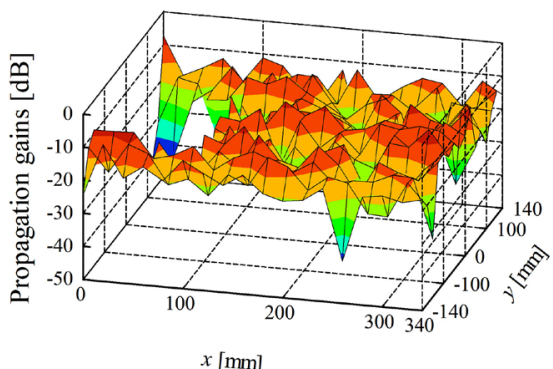

(a)

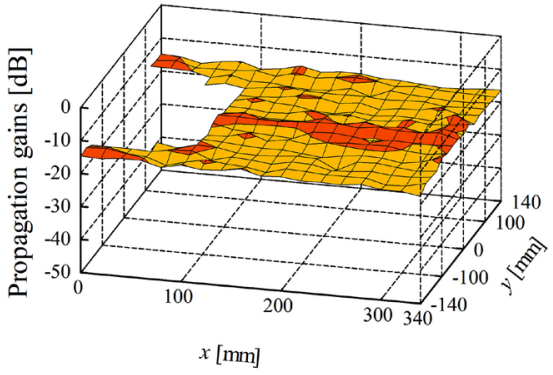

(c)

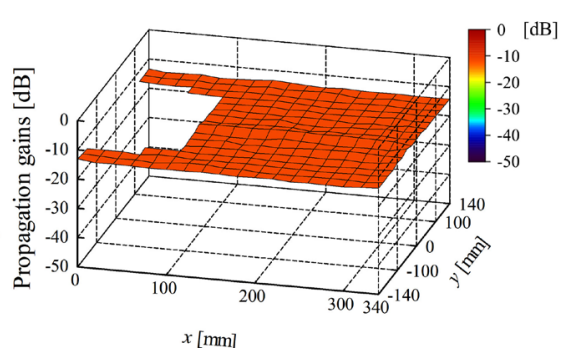

(b)

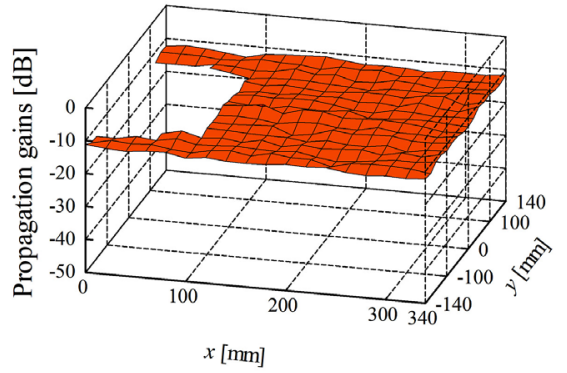

(d)

Figure 8. Distributions of propagation gains within the shield box with no apertures for: (a) CW and (b) full-, (c) low-, and (d) high-band UWB [10].

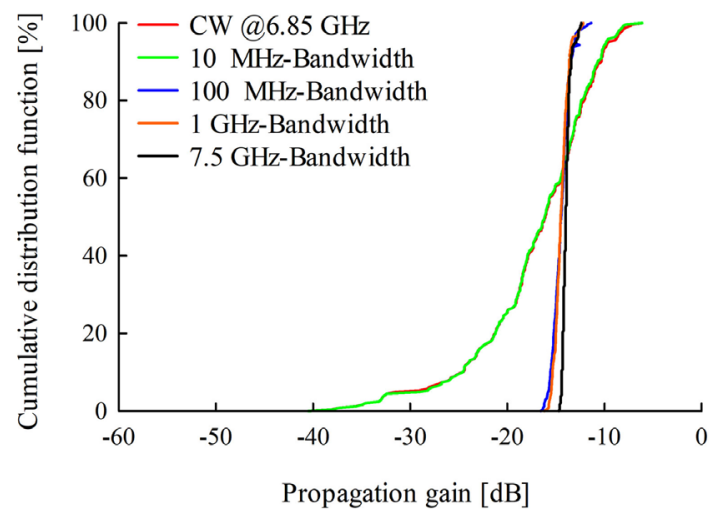

(a)

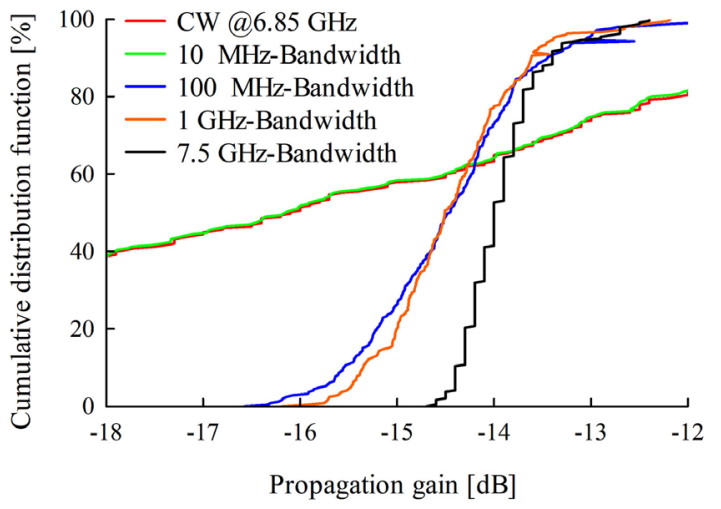

(b)

Figure 9. CDFs of UWB propagation gain measured within the shield box without apertures. Propagation gain ranged (a) -60 to $0 \mathrm{~dB}$ and (b) -18 to $-12 \mathrm{~dB}$. 


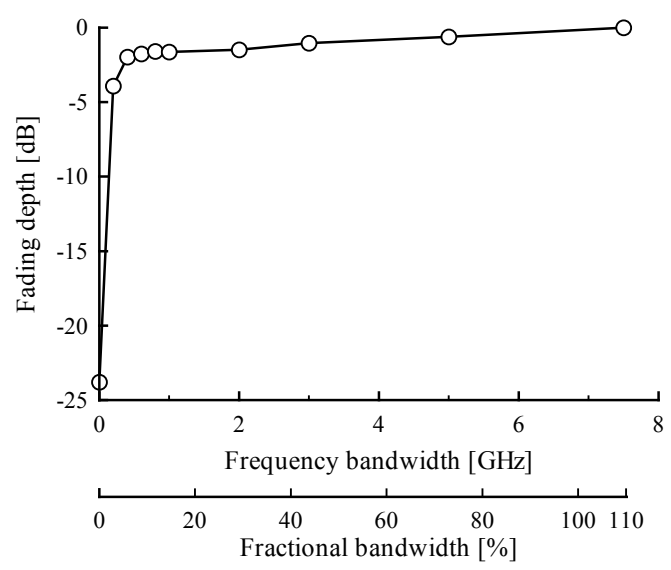

Figure 10. Fading depth versus occupied bandwidth at the deepest dead spot within the shield box without apertures [10].

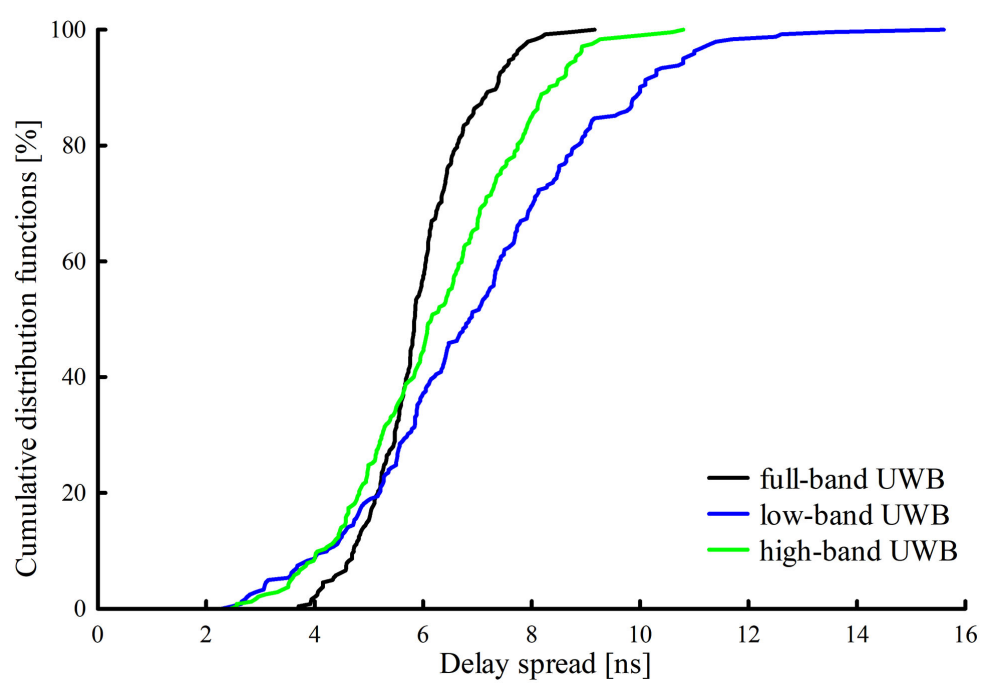

Figure 11. CDFs of delay spread within the shield box without apertures.

With apertures. The UWB propagation gains were almost invariable for the total area of apertures between $10^{-4}$ and $10^{-3} \mathrm{~m}^{2}$ or the relative area of the apertures between $0.01 \%$ and $0.1 \%$, and gradually decreased with the area beyond $10^{-3} \mathrm{~m}^{2}$ or $0.1 \%$, as shown in Figure 12. The UWB propagation gain with apertures was found approximately $-7.5 \mathrm{~dB}$ lower than that without them in average. This was attributed to radiofrequency power leakage through the apertures to the outside. The lower UWB propagation gains in the high-band UWB were ascribable to larger free space propagation losses. CDFs of the UWB propagation gain in the box with apertures are plotted in Figure 13. Medians (at which CDF $=50 \%)$ were found with apertures:

$-15.9 \mathrm{~dB}$ for full-band UWB,

$-15.2 \mathrm{~dB}$ for low-band UWB, and

$-17.8 \mathrm{~dB}$ for high-band UWB.

The UWB propagation gains near the apertures did not exhibit different behavior from those in the other regions. 


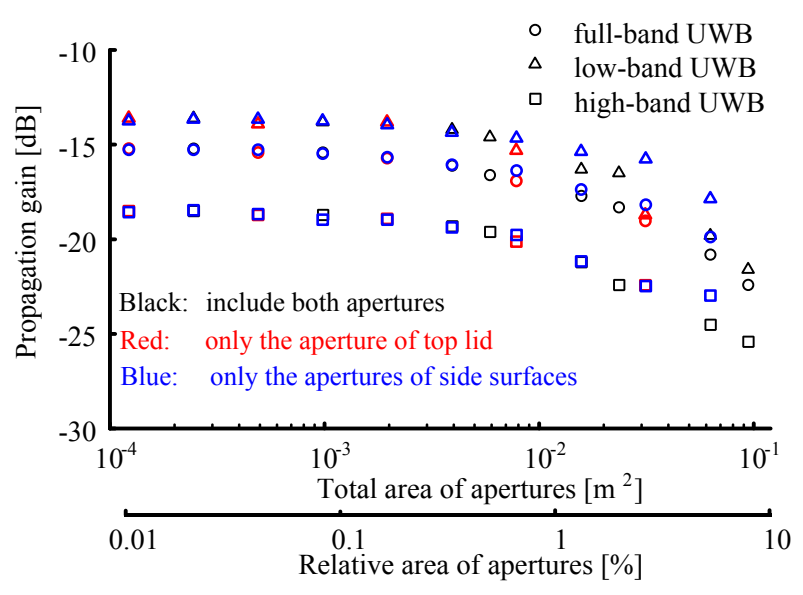

Figure 12. UWB Propagation gains measured versus total area of apertures.

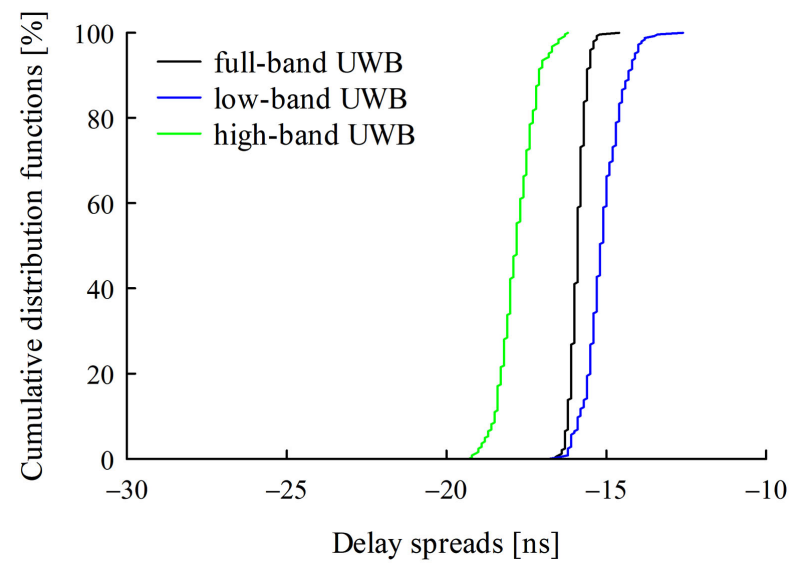

Figure 13. CDFs of propagation gain within the shield box with apertures (total area $=9.4 \times 10^{-2} \mathrm{~m}^{2}$ ).

The delay spreads were found at less than $10 \mathrm{~ns}$ for the shield box with apertures, and more than 45 ns without aperture. The conductive shield box without apertures caused abundant multipath. The long delays were suppressed with apertures. Spatial distributions of the delay spread with apertures are shown in Figure 14 with apertures (total area $=9.4 \times 10^{-2} \mathrm{~m}^{2}$ ). The delay spreads were gradually decreased, as shown in Figure 15 . The delay profiles and the delay spreads were found statistically invariable between the regions near and far from the apertures.

The link throughputs were measured with use of a pair of WiMedia devices, one of which was links to a solid state drive (SSD) via USB 2.0 interface, and the other was connected to a personal computer with a built-in SSD via a PCMCIA interface. Since the throughputs fluctuated typically $\pm 4 \mathrm{Mb} / \mathrm{s}$ per trial, a number of trials (normally 35) were carried out to reduce the variation within $\pm 1 \mathrm{Mb} / \mathrm{s}$. The throughputs measured at $(300,0)$ were limited approximately beneath 72 Mbps below the total aperture area of $4.0 \times 10^{-3} \mathrm{~m}^{2}$, and gradually increased with the area beyond $3 \times 10^{-3} \mathrm{~m}^{2}$, as shown in Figure 16 . 


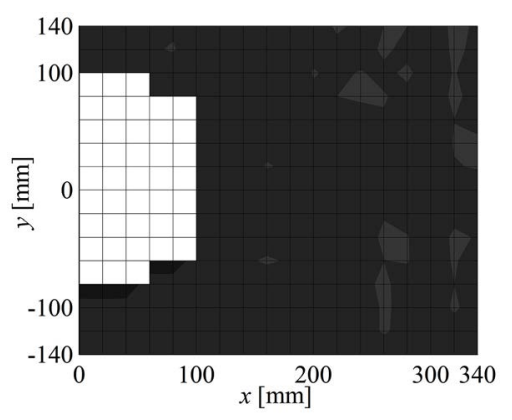

(a)

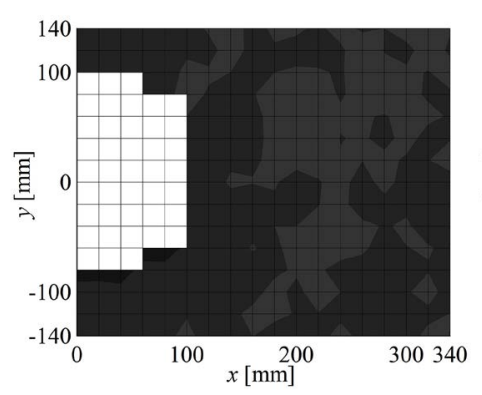

(b)

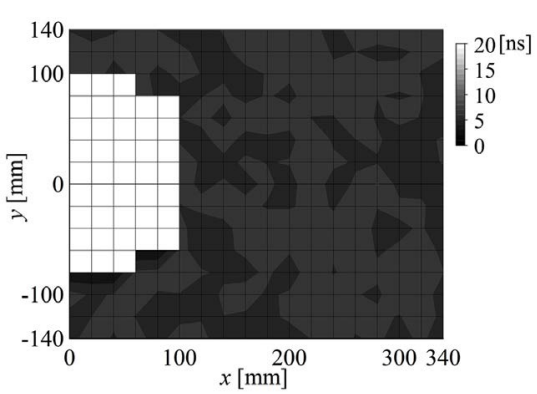

(c)

Figure 14. Distribution of delay spreads, measured with apertures (total area $=9.4 \times 10^{-2}$ $\mathrm{m}^{2}$ ) for: (a) full- (3.1 - 10.6 GHz), (b) low- (4.2 - 4.8 GHz), and (c) high-band UWB (7.4 $7.9 \mathrm{GHz})$.

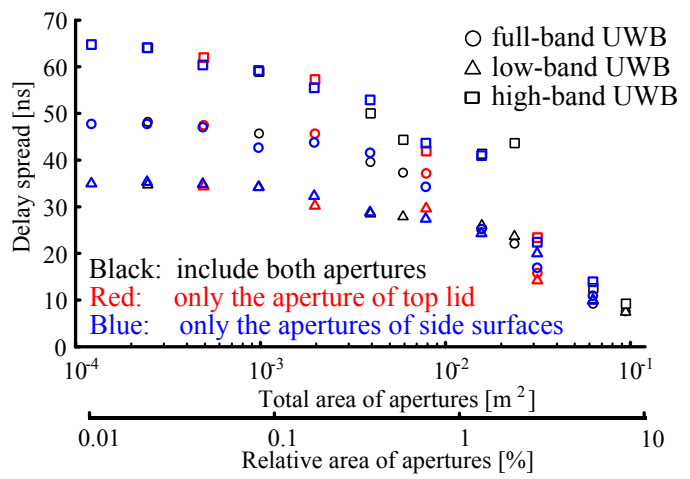

Figure 15. Delay spreads measured versus total area of apertures.

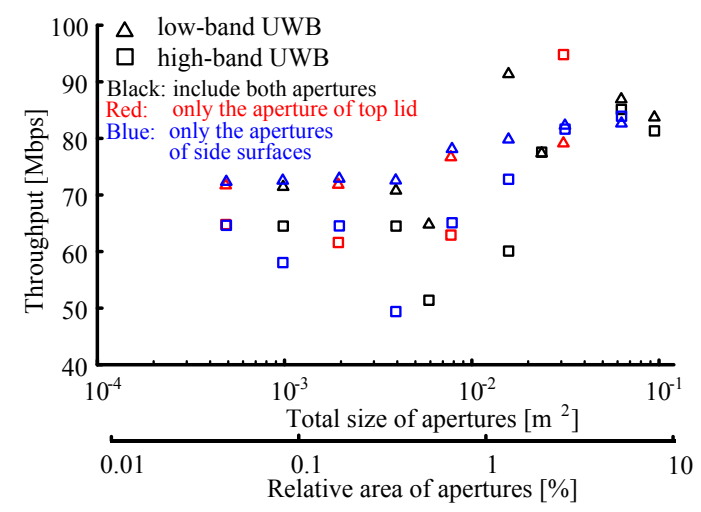

Figure 16. Throughputs versus total area of apertures. 


\section{Effects of Radio Absorbers inside the Box}

The authors revealed that a small piece of radio absorber panel can suppress the long delay spreads even in a shield box [5]. A flat, rectangular, 2-mm thick radio absorber panel can suppress the long delay spreads even in a shield box, as shown in Figure 17. The spatial distributions of the delay spread for low- and high-band UWB are presented in Figure 18 with use of the radio absorber covering $8 \%$ of the total inner surface. The delay spread ranged 2.3 - 16 ns for the low- and 2.4 - $11 \mathrm{~ns}$ for high-band UWB, respectively. The spatial distributions of the average throughput measured with use of the WiMedia devices are presented in Figure 19. No apparent dependence on the antenna distance was observed, either. The throughput ranged 88 - 102 and 88 - $100 \mathrm{Mbps}$ for low- and high-band UWB, respectively. The spatial distributions of the UWB propagation gain, the delay spreads, and the throughputs exhibited no noticeable correlation. While the absorber panel was places in the center of the bottom of the box in this experiment, Sasaki et al. reported that radio reverberation characteristics was almost independent of the position of a small piece of absorber lining within a shielding chamber [17].

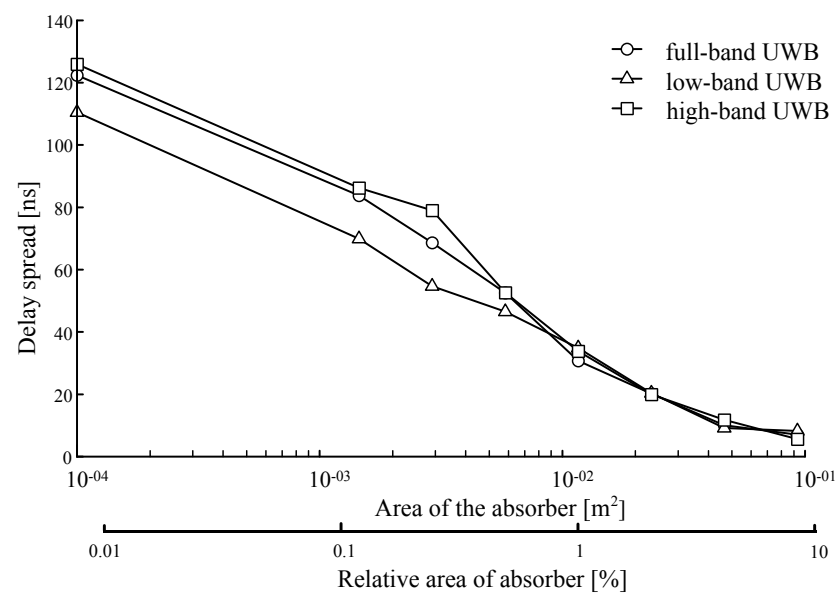

Figure 17. Throughputs measured versus total area of radio absorbers.

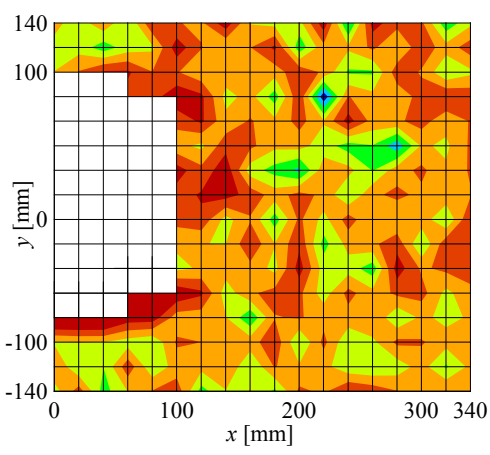

(a)

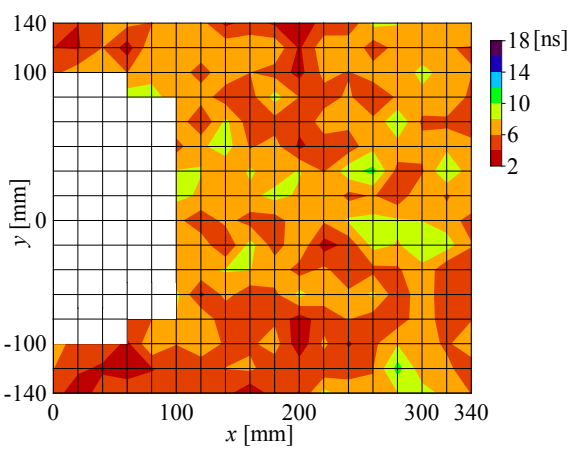

(b)

Figure 18. Distribution of delay spread with use of $8 \%$ area of the radio absorber: (a) lowand (b) high-band UWB. 


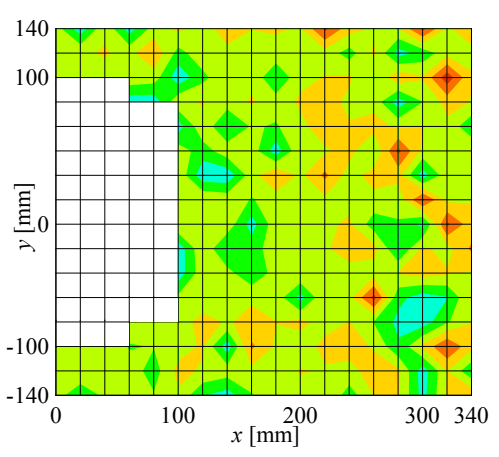

(a)

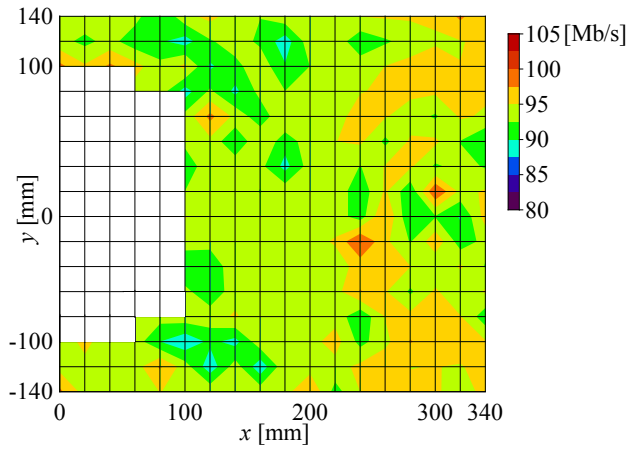

(b)

Figure 19. Spatial distribution of throughput with use of $8 \%$ area of the radio absorber: (a) low- and (b) high-band UWB.

\section{Conclusions}

In this study, ultra wideband (from $3.1-10.6 \mathrm{GHz}, 4.2-4.8 \mathrm{GHz}$, and $7.4-7.9$ $\mathrm{GHz})$ and $\mathrm{CW}(6.85 \mathrm{GHz})$ propagation and transmission were measured and characterized inside an MTM and a shield box emulating a small spacecraft. While CW resulted in nearly $35-\mathrm{dB}$ fading at several "dead spots" caused by multipath environment, UWB yielded none. The UWB systems have therefore an advantage over narrowband from the viewpoint of reducing fading margins. A bandwidth over $500 \mathrm{MHz}$ was capable of reducing the fading depth by approximately $3 \mathrm{~dB}$ in conductive semi-closed spaces like spacecraft. No dependence on the distance was observed for UWB propagation gain, delay spread, or throughput, and no apparent spatial correlation between them. The UWB propagation and link throughput were also evaluated inside a shield box. Larger spaces and/or the conductive enclosures (such as larger spacecrafts) yielded longer delay spreads, in general. The longer delay spreads, however, can be suppressed due to either the existence of apertures on surface or the artificial placement of radio absorbers, as derived in Section III and IV. Correspondingly wireless links can be applied to larger spacecrafts.

Future study and concerns include dependence on the inner volume, modeling of channel responses within spacecrafts, and electromagnetic compatibility between onboard equipment (particularly uplink microwave receiver) and the UWB devices.

\section{Acknowledgements}

The authors would also like to express special thanks to Akihisa Matsubara and Shinichiro Hamada for help with the experiments and valuable discussions. I greatly appreciate the support and encouragement of the late Prof. Takehiko Kobayashi.

\section{Conflicts of Interest}

The authors declare no conflicts of interest regarding the publication of this paper. 


\section{References}

[1] Amini, R., et al. (2006) New Generations of Spacecraft Data Handling Systems: Less Harness, More Reliability. 57 th International Astronautical Congress, Valencia, 2-6 October 2006, 1.

[2] Gineste, P.-N., et al. (2012) Assessment of Wireless Link Budget in a Satellite by Modelling Techniques. Proceedings of 2012 ESA Workshop on Aerospace EMC, Venice, 21-23 May 2012, 1-6.

[3] Toda, T., Kukutsu, N., Kitazawa, S., Ano, S., et al. (2016) Intra-Spacecraft Wireless Link and Its Application to Spacecraft Environmental Tests. Transactions of the Japan Society for Aeronautical and Space Sciences, Aerospace Technology Japan, 14, 21-26. https://doi.org/10.2322/tastj.14.Pj_21

[4] Pelissou, P., Lachaud, R., Dallemagne, Ph., Decotignie, J.-D. and Dufour, J.-F. (2014) Simulated IEEE 802.15.4a BER Results (Multipath and Coexistence) in the Spacecraft Environment. Proceedings of IEEE International Conference on Wireless for Space and Extreme Environments, Noordwijk, 30-31 October 2014, 1-5. https://doi.org/10.1109/WiSEE.2014.6973082

[5] Matsubara, A., Tomiki, A., Toda, T. and Kobayashi, T. (2011) Measurements and Characterization of Ultra Wideband Propagation within Spacecrafts-Proposal of Wireless Transmission for Replacing Wired Interface Buses. Antennas \& Propagation Conference, Loughborough, 16-17 November 2009, 61-74.

https://doi.org/10.5772/13772

[6] Heuvel, J.H.C., Romme, J., Dufour, J.F., et al. (2013) UWB Radio Channel Characterization and Design for Intra Spacecraft Communication. Proceedings of IEEE International Conference on Communications, Budapest, 9-13 June 2013, 5311-5316.

[7] Chandra, A., Prokeš, A., Mikulášek, T., Blumenstein, J., et al. (2016) Frequency-Domain In-Vehicle UWB Channel Modeling. IEEE Transactions on Vehicular Technology, 65, 3929-3940. https://doi.org/10.1109/TVT.2016.2550626

[8] Andersen, J.B., Chee, K.L., Jacob, M., Pedersen, G.F. and Kurner, T. (2012) Reverberation and Absorption in an Aircraft Cabin with the Impact of Passengers. IEEE Transactions on Antennas and Propagation, 60, 2472-2480. https://doi.org/10.1109/TAP.2012.2189700

[9] Gelabelt, J., Kavatjikidis, A., Edwards, D.J. and Stevens, C.J. (2009) Experimental UWB Channel Characterization of an Electromagnetically Small Environment. Loughborough Antennas \& Propagation Conference, Loughborough, 16-17 November 2009, 381-384. https://doi.org/10.1109/LAPC.2009.5352442

[10] Hirose, M. and Kobayashi, T. (2016) Measurements of UWB Propagation and Transmission for Wireless Links in Spacecrafts. The 8th International Conference on Advances in Satellite and Space Communications, Lisbon, February 2016, 12-17.

[11] Kobayashi, T. and Hirose, M. (2015) Wideband and Ultra Wideband Radio Propagation in Heavy Multipath Environments. IEICE Trans. Fundamentals, E98-A, 511-519.

[12] Taniguchi, T., Maeda, A. and Kobayashi, T. (2006) Development of an Omnidirectional and Low-VSWR Ultra Wideband Antenna. International Journal on Wireless and Optical Communications, 3, 145-157.

https://doi.org/10.1142/S0219799506000442

[13] Heidari, G. (2008) WiMedia UWB-Technology of Choice for Wireless USB and Bluetooth. John Wiley \& Sons, New York. https://doi.org/10.1002/9780470715598 
[14] European Cooperation for Space Standardization, Standard ECSS-E-ST-50-12C (2008) SpaceWire-Links, Nodes, Routers and Networks.

[15] Matsushita, T., Tomiki, A. and Kobayashi, T. (2015) Highly Reliable UWB-OFDM Transmission within a Small Spacecraft. Proceedings of 1 st URSI Atlantic Radio Science Conference, Las Palmas, 16-24 May 2015, 1. https://doi.org/10.1109/URSI-AT-RASC.2015.7302967

[16] Molisch, A.F., et al. (2004) IEEE 802.15.4a Channel Model-Final Report. Submitted to IEEE 802.15 WPAN Low Rate Alternative PHY Task Group 4a (TG4a).

[17] Sasaki, K., Oshima, I. and Karasawa, Y. (2008) A Reverberation Chamber to Realize Multipath-Rich Environment [II]-Environment Control by Electromagnetic Wave Absorbing Sheet. IEICE Technical Report, 108, 13-18. (In Japanese) 